OPEN ACCESS

Edited by:

Mark Preul,

Barrow Neurological Institute (BNI),

United States

Reviewed by:

Guolin $\mathrm{Ma}$

China-Japan

Friendship Hospital, China

Di Dong,

Institute of Automation (CAS), China

*Correspondence:

Jonathan T. C. Liu

jonliu@uw.edu

${ }^{\dagger}$ Co-first authors

Specialty section:

This article was submitted to

Cancer Imaging and Image-directed

Interventions,

a section of the journa

Frontiers in Oncology

Received: 02 April 2019

Accepted: 17 June 2019

Published: 03 July 2019

Citation:

Wei L, Fujita Y, Sanai N and Liu JTC

(2019) Toward Quantitative

Neurosurgical Guidance With High-Resolution Microscopy of

5-Aminolevulinic Acid-Induced

Protoporphyrin IX.

Front. Oncol. 9:592

doi: 10.3389/fonc.2019.00592

\section{Toward Quantitative Neurosurgical Guidance With High-Resolution Microscopy of 5-Aminolevulinic Acid-Induced Protoporphyrin IX}

\author{
Linpeng Wei ${ }^{1+}$, Yoko Fujita ${ }^{2 \dagger}$, Nader Sanai ${ }^{2}$ and Jonathan T. C. Liu ${ }^{1,3 *}$ \\ ${ }^{1}$ Department of Mechanical Engineering, University of Washington, Seattle, WA, United States, ${ }^{2}$ Department of Neurological \\ Surgery, Barrow Neurological Institute, Phoenix, AZ, United States, ${ }^{3}$ Department of Pathology, University of Washington \\ School of Medicine, Seattle, WA, United States
}

Low-power fluorescence microscopy of 5-ALA-induced PpIX has emerged as a valuable intraoperative imaging technology for improving the resection of malignant gliomas. However, current fluorescence imaging tools are not highly sensitive nor quantitative, which limits their effectiveness for optimizing operative decisions near the surgical margins of gliomas, in particular non-enhancing low-grade gliomas. Intraoperative high-resolution optical-sectioning microscopy can potentially serve as a valuable complement to low-power fluorescence microscopy by providing reproducible quantification of tumor parameters at the infiltrative margins of diffuse gliomas. In this forward-looking perspective article, we provide a brief discussion of recent technical advancements, pilot clinical studies, and our vision of the future adoption of handheld optical-sectioning microscopy at the final stages of glioma surgeries to enhance the extent of resection. We list a number of challenges for clinical acceptance, as well as potential strategies to overcome such obstacles for the surgical implementation of these in vivo microscopy techniques.

Keywords: fluorescence-guided surgery, handheld microscopy, 5-ALA, PpIX, gliomas, quantitative imaging

\section{INTRODUCTION}

Gliomas are the most common primary malignant brain tumors, with $\sim 20,000$ new cases each year in the United States (1). As the standard-of-care for all grades of gliomas, patients generally receive surgery as a first-line treatment. The goal of this "debulking" surgery is to maximize the extent of resection (EOR) while avoiding neurological damage. Mounting evidence suggests that moreextensive EOR is associated with increased overall survival and progression-free survival for both low- and high-grade gliomas patients (2-11). Unfortunately, optimal EOR is not achieved in many patients due to the lack of effective technologies to delineate tumor margins intraoperatively, with reported rates of gross-total resection (GTR) for high-grade gliomas (HGGs) ranging from 33 to $76 \%(12-19)$ and for low-grade gliomas (LGGs) ranging from 14 to $46 \%(7-9,20,21)$.

In recent years, numerous reports have detailed the benefits of using 5 -aminolevulinic acid (5-ALA) for guiding HGG resections (22-38). In brief, 5-ALA is a non-fluorescent prodrug that is orally administered to patients several hours prior to surgery. 5-ALA is then intra-cellularly metabolized to form a fluorescent byproduct, protoporphyrin IX (PpIX), a heme-synthesis pathway 
substrate that accumulates preferentially in glioma cells due to metabolic dysregulation (39-43). In most cases, after 5-ALA administration, the bulk of a HGG tumor emits visible red fluorescence $(\sim 630 \mathrm{~nm})$ when excited with blue $(\sim 405 \mathrm{~nm})$ illumination, as viewed by the unassisted eye or with a wide-field fluorescence surgical microscope. A landmark phase III trial in Europe by Stummer et al. demonstrated that the use of this technique resulted in higher rates of GTR (65 vs. 36\%) and 6-month progression-free survival (41 vs. $21.1 \%$ ) compared to control patients (37). Intraoperative 5-ALA-induced fluorescence has since emerged as a valuable adjunct for HGG surgeries (22, 35-38), and has recently been approved by the US Food and Drug Administration (FDA) for neurosurgical guidance in 2017 (44).

In spite of its clear benefits, 5-ALA-based fluorescence-guided surgery (FGS) suffers from a number of shortcomings. First, it remains ineffective for guiding the resections of most LGGs and at the infiltrative margins of all diffuse gliomas (low- and highgrade) due to the fact that PpIX accumulation in these tissues is typically below the detection limit of conventional low-power wide-field surgical microscopes. Second, the visible fluorescence generated by PpIX is interpreted subjectively (45) and is difficult to quantify. This is because the visualized fluorescence is greatly affected by light-tissue interactions such as absorption and scattering, as well as detection parameters such as the angle and working distance of the microscope $(46,47)$. In light of these concerns, spectroscopy-based methods have been developed to provide a more accurate and reproducible measurement of the absolute concentration of PpIX expression in tissue, in which mathematical models are used to correct for the aforementioned confounding effects $(22,48-51)$. These quantitative detection methods should enable more-objective decision-making during tumor resection since the degree of PpIX accumulation has been shown to correlate with proliferative index, mitochondrial content, and other clinicopathologic metrics $(22,23,40,52,53)$. However, while probe-based spectroscopy can provide improved sensitivity to detect weak PpIX fluorescence (i.e., in LGGs or at the tumor margins of all gliomas) in comparison to conventional wide-field surgical microscopy (54), spectroscopic approaches are typically limited to sampling localized points of tissue at low spatial resolution rather than generating an image over an extended field of view (FOV).

As a high-resolution, high-contrast imaging technique, handheld confocal microscopy has been explored as an alternative solution to guide the resection of both LGGs and HGGs. In 2011, a pilot study by Sanai et al. first demonstrated the feasibility of using a handheld in vivo confocal microscope to detect PpIX expression in LGGs (55), in which conventional wide-field surgical microscopy lacked the sensitivity to detect the PpIX fluorescence. Although the raw intensity of PpIX fluorescence, as previously mentioned, is subjective and cannot be reliably quantified, the spatial distribution (e.g., size, density, localization, etc.) of the signal can potentially serve as a reproducible tumor biomarker (56). Most recently, highspeed handheld confocal microscopy with video-mosaicking capabilities have also been developed and are continuing to be refined for 5-ALA-based FGS (57). In this perspective article, we outline a vision for a clinical workflow in which quantitative high-resolution microscopy is implemented to achieve optimal EOR for the ultimate benefit of patients suffering from LGGs and HGGs. We also describe key challenges to overcome and potential strategies to facilitate the clinical acceptance of these new technologies.

\section{QUANTITATIVE PPIX VISUALIZATION WITH OPTICAL-SECTIONING MICROSCOPY}

Optical-sectioning microscopy enables cross-sectional imaging of intact tissue at shallow depths $(<0.5 \mathrm{~mm}$ deep) by removing the background "haze" due to out-of-focus and multiply-scattered photons. A technical description of various optical-sectioning approaches has been provided in previous review articles (58-61). In general, optical-sectioning microscopy provides the superior image contrast and spatial resolution that is necessary to detect the weak and sparse PpIX fluorescence generated by LGGs and at the infiltrative margins of all diffuse gliomas (55). An increasing number of studies have showcased the feasibility to examine PpIX expression in human gliomas at the microscopic level using optical-sectioning techniques $(55,56,62,63)$. Microscopic PpIX expression in gliomas is manifested as localized subcellular foci of fluorescence, a pattern that is consistent with our current biological understanding of subcellular PpIX generation by mitochondria (43). Quantification of microscopic PpIX expression based on a tabletop line-scanned dual-axis-confocal (LS-DAC) microscopy-a high-speed, high-contrast optical-sectioning technique-has been shown to agree with conventional fluorescence histology (56), suggesting that a miniature LS-DAC device could serve as a real-time non-invasive alternative to slide-based histopathology. As detailed in a recent review (47) and summarized in Figure 1, the main trade-off for high-resolution microscopy is a limited FOV that can lead to sampling bias in glioma tissues that are often spatially heterogeneous. To mitigate this problem, handheld confocal microscopy with video-mosaicking (i.e., stitching overlapping video frames to create an extended FOV over time using image processing algorithms) have been developed to sample a tissue region comparable in size to a physical biopsy specimen (several millimeters in scale) while maintaining high resolution and contrast $(57,64-68)$.

\section{PROPOSED CLINICAL WORKFLOW}

In the current clinical workflow for 5-ALA-based FGS, glioma margins are defined by pre-operative or intraoperative magnetic resonance imaging (MRI), as well as wide-field (low-power) surgical microscopy. However, since all gliomas are diffuse and ill-defined, the contrast-enhancing regions revealed by these wide-field imaging methods (e.g., Gd-enhancement for HGGs, T2-hyperintensity for LGGs, and macroscopic PpIX fluorescence for most HGGs) are not indicative of the actual extent of tumor infiltration. While frozen-section histopathology can confirm 


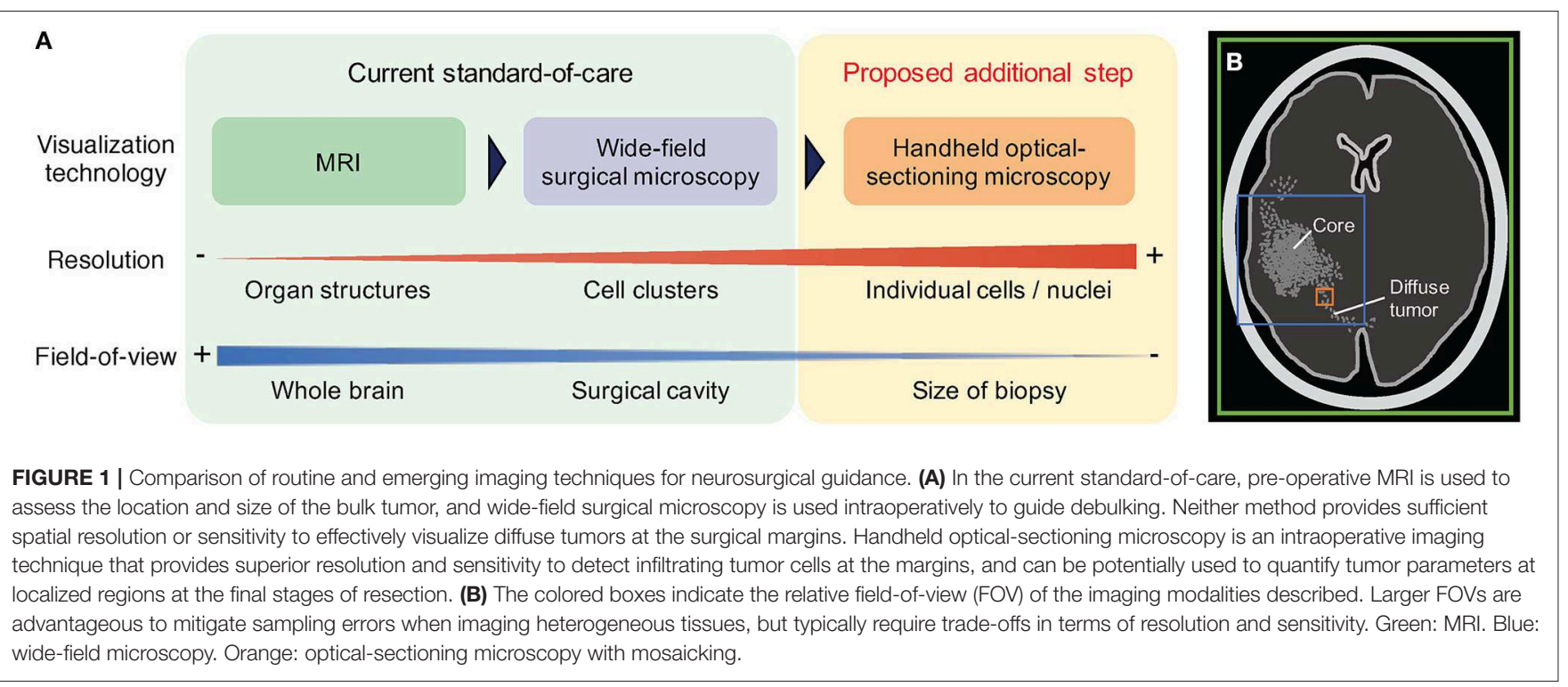

tissue status during the course of glioma resection, this strategy is invasive (requiring a physical biopsy) and time consuming. Our hypothesis, to be investigated in future prospective studies, is that when operating on gliomas adjacent to eloquent cortical and subcortical pathways, quantitative high-resolution microscopy can be used at the final stages of resection to interrogate tumor burden and other quantitative biomarkers at multiple suspicious sites in order to optimize the EOR (including beyond the radiographic margins) without jeopardizing functional pathways. As shown in Figure 2, a specific workflow for future clinical use is provided below:

(1) At the initial stages of the surgery, standard neurosurgical methods will be used for debulking the central portions of the tumor. As the neurosurgeon approaches the radiographic or functional boundaries of the tumor (indicated by anatomical/visual cues, MRI-based neuronavigation, intraoperative stimulation mapping, and 5-ALA-based FGS using wide-field surgical microscopy), regions adjacent to noneloquent brain can be resected more aggressively to minimize residual tumor burden.

(2) At the final stages of surgery, ambiguous regions at critical locations (e.g., near eloquent brain) will be probed with highresolution video-mosaicked microscopy of the exposed tissue surfaces, enabling a quantitative measure of microscopic PpIX expression that should ideally correlate with clinicopathologic metrics such as tumor burden and proliferative/mitotic index in order to guide operative decision-making. This provides a noninvasive and real-time alternative to intraoperative consultation with frozen-section histology. It should be noted that similar sterile probe-based microscopy/spectroscopy strategies have been implemented during neurosurgeries, as described in several reports (69-73).

(3) Conventional surgical tools (e.g., ultrasonic aspirator, suction catheters, etc.) will be used in an iterative process with intraoperative microscopy until optimal resection has been achieved. Ideally, neuronavigation would be used to track the spatial coordinates of all surgical devices (microscope, suction catheters, etc.) to ensure good co-registration between iterative rounds of imaging and resection.

\section{CHALLENGES AND FUTURE STEPS}

A number of translational milestones should ideally be achieved in order to bolster confidence in a high-resolution intraoperative imaging technique for adoption by surgeons. First, and perhaps the most critical step, is to establish a biological context and understanding of the pattern of sub-cellular PpIX expression that is visualized with an optical-sectioning microscope. Note that numerous studies have already shown that PpIX expression provides specific delineation of a variety of neoplasms under wide-field (low-resolution) imaging and spectroscopy (52, 74, 75), including a general correlation between PpIX concentrations and proliferative score as well as World Health Organization (WHO) histologic score (52). Preliminary studies [e.g., using high-resolution in vivo microscopy (55), or using fluorescentactivated cell sorting of dissociated human cells [unpublished data]] have also shown that PpIX expression at the cellular level is highly tumor-specific. However, larger-scale correlation studies are needed to improve our ability to interpret high-resolution images of PpIX in gliomas. For example, studies should ideally demonstrate a clear correlation between subcellular patterns of PpIX fluorescence and well-established clinicopathologic metrics such as tumor burden and proliferative/mitotic index (e.g., Ki-67 and $\mathrm{pHH} 3$ expression). Facilitated by the recent advancements in both imaging hardware [e.g., open-top light-sheet microscopy (63)] and artificial intelligence (e.g., deep-learning algorithms for classification and regression tasks), it should be possible to perform large correlative studies within a reasonable timeline. A second milestone, as mentioned previously, is to mitigate sampling bias due to tissue heterogeneity and to more-closely match the spatial precision of current surgical tools (typically several millimeters in scale). While it is technically challenging 


\section{Initial stage: Debulking guided by low-power surgical microscopy}

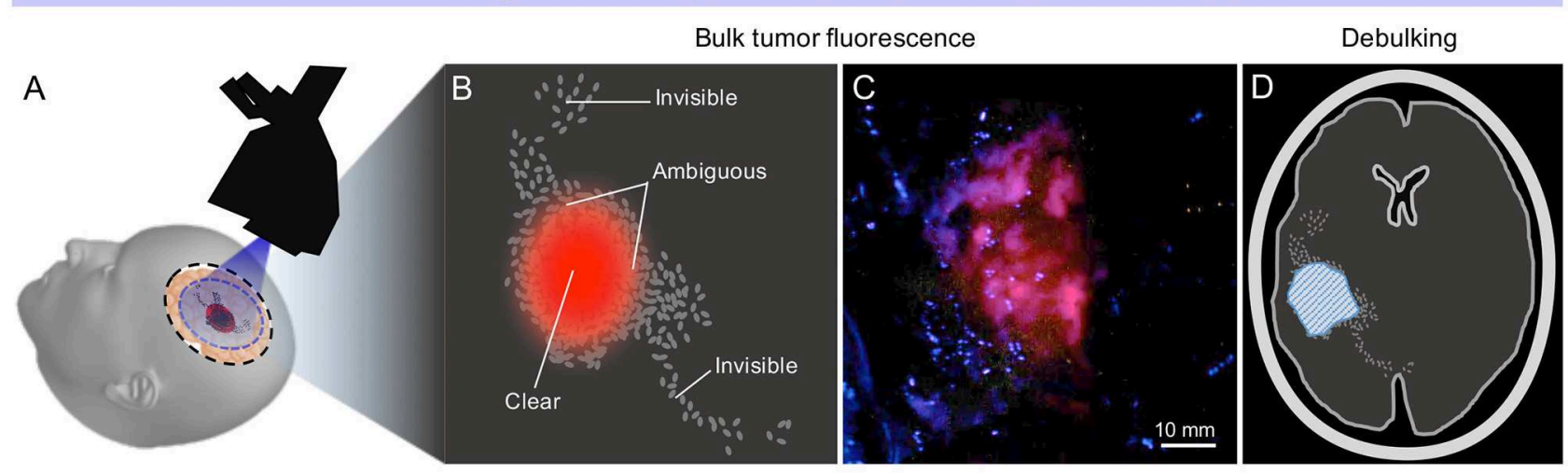

Final stage: Enhanced resection enabled by high-resolution microscopy

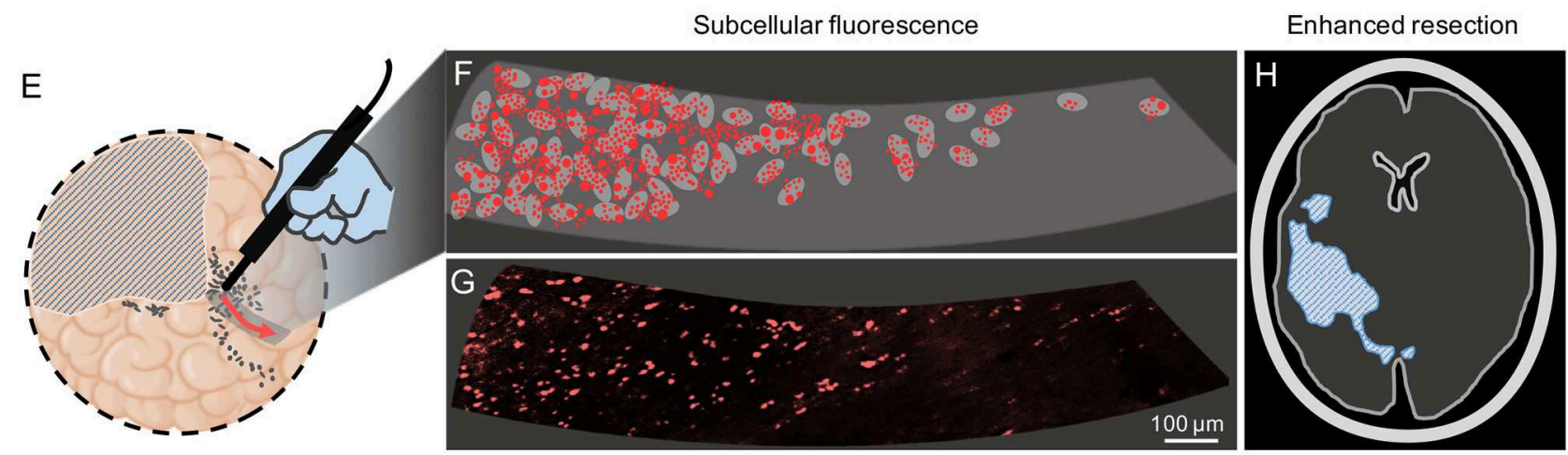

Macroscopic
fluorescence

Mosaicked FOV

Resected tumor

FIGURE 2 | Proposed clinical workflow of 5-ALA-based fluorescence-guided neurosurgery. (A) Conventional low-power fluorescence surgical microscopy provides a wide FOV that often covers the entire surgical cavity. (B) Macroscopic PpIX fluorescence is visible at the central portions of most HGGs, but not at the infiltrative margins. (C) Example low-power fluorescence microscopy image of PpIX expression from a bulk HGG region. The margins of the tumor are subjectively delineated and ambiguous. (D) Debulking guided by macroscopic PpIX fluorescence, resulting in residual tumor burden. (E) High-sensitivity probe-based optical-sectioning microscopy is used to examine localized regions near the surgical margins, providing a non-invasive alternative to intraoperative frozen section histopathology. (F) Visualization of subcellular PpIX fluorescence can potentially enable quantification of tumor parameters in order to guide surgical decisions at the final stages of resection. (G) Example image of microscopic PpIX fluorescence in a HGG biopsy using high-resolution optical-sectioning microscopy. (H) Optimal extent of resection is achieved after iterative tumor resection guided by video-mosaicked handheld optical-sectioning microscopy.

to engineer high-resolution microscopes with such large FOVs, robust computer vision algorithms have been developed and continue to be refined to stitch overlapping image frames together to create an extended FOV in real time while an imaging device is translated along the tissue surface $(57,64-68)$.

It bears repeating that the goal of optical-sectioning microscopy is NOT to image deeply, but rather to perform quantitative imaging near the exposed tissue surface, which requires the high contrast of an optical-sectioning device. However, in practice, the ability to image over a shallow range of depths ( $<150$ microns) may be of practical value to identify an optimal depth where image quality and tissue integrity are maximized. Complementary imaging modalities for detecting
PpIX fluorescence from deep subsurface tumors (76-78) are beyond the scope of this perspective paper. In terms of resolution, since current resection tools lack the spatial precision of a high-resolution microscope, the value of high-resolution imaging is not to enable cellular-scale resection, but to enable accurate quantification of PpIX, which in turn should correlate with relevant metrics of tumor burden/proliferation to guide surgical decisions. As with all innovative technologies, clinical validation is needed through well-powered and controlled studies. For example, "malignancy scores" based on quantitative PpIX microscopy should agree with traditional assessment methods such as histopathology and post-operative MRI, and should also be predictive of patient outcomes (e.g., recurrence). Note that 
for most glioma patients, adjuvant radiotherapy is a logical nextstep following tumor resection. The development of technology that enables microscopic quantification of tumor burden and proliferation, and therefore identification of resection cavity regions with high-risk of tumor recurrence, could also inform postoperative radiotherapy planning and improve the efficacy of radiation-based strategies to control tumor progression.

In summary, the recent FDA approval of 5-ALA-based FGS and the advancement of fluorescence imaging technologies have provided a unique opportunity to improve glioma surgeries. We believe that handheld video-mosaicked optical-sectioning microscopy has an important role to play in improving the EOR for glioma surgeries through quantitative and reproducible delineation of the infiltrative margins of diffuse gliomas, for which current techniques fail to provide adequate guidance at the final most-critical stages of resection procedures. The successful translation of this technology will require collaborative efforts amongst multidisciplinary teams that include optical engineers, neurosurgeons, pathologists/biologists, computer scientists, industry partners, and regulatory/reimbursement stakeholders.

\section{REFERENCES}

1. Ostrom QT, Gittleman H, Liao P, Vecchione-Koval T, Wolinsky Y, Kruchko C, et al. CBTRUS Statistical report: primary brain and other central nervous system tumors diagnosed in the United States in 2010-2014. Neuro Oncol. (2017) 19(suppl_5):v1-v88. doi: 10.1093/neuonc/nox158

2. Hervey-Jumper SL, Berger MS. Evidence for improving outcome through extent of resection. Neurosurg Clin N Am. (2019) 30:85-93. doi: 10.1016/j.nec.2018.08.005

3. Lau D, Hervey-Jumper SL, Han SJ, Berger MS. Intraoperative perception and estimates on extent of resection during awake glioma surgery: overcoming the learning curve. J Neurosurg. (2018) 128:1410-8. doi: 10.3171/2017.1.JNS161811

4. Sharma M, Bellamkonda S, Mohapatra S, Meola A, Jia X, Mohammadi $\mathrm{A}$, et al. Correlation between the residual tumor volume, extent of tumor resection, and O6-methylguanine DNA methyltransferase status in patients with glioblastoma. World Neurosurg. (2018) 116:e147-e61. doi: 10.1016/j.wneu.2018.04.134

5. Ahmadi R, Rezvan A, Dictus C, Christine D, Hartmann C, Christian H, et al. Long-term outcome and survival of surgically treated supratentorial low-grade glioma in adult patients. Acta Neurochir. (2009) 151:135965. doi: 10.1007/s00701-009-0435-x

6. Keles GE, Lamborn KR, Berger MS. Low-grade hemispheric gliomas in adults: a critical review of extent of resection as a factor influencing outcome. $J$ Neurosurg. (2001) 95:735-45. doi: 10.3171/jns.2001.95.5.0735

7. McGirt MJ, Chaichana KL, Attenello FJ, Weingart JD, Than K, Burger PC, et al. Extent of surgical resection is independently associated with survival in patients with hemispheric infiltrating low-grade gliomas. Neurosurgery. (2008) 63:700-7-author reply 7-8. doi: 10.1227/01.NEU.0000325729.41085.73

8. Sanai N, Polley M-Y, Berger MS. Insular glioma resection: assessment of patient morbidity, survival, and tumor progression. J Neurosurg. (2010) 112:1-9. doi: 10.3171/2009.6.JNS0952

9. Smith JS, Chang EF, Lamborn KR, Chang SM, Prados MD, Cha S, et al. Role of extent of resection in the long-term outcome of low-grade hemispheric gliomas. J Clin Oncol. (2008) 26:1338-45. doi: 10.1200/JCO.2007.13.9337

10. Stummer W, van den Bent MJ, Westphal M. Cytoreductive surgery of glioblastoma as the key to successful adjuvant therapies: new arguments in an old discussion. Acta Neurochir. (2011) 153:1211-8. doi: 10.1007/s00701-011-1001-x

11. Stummer W, Reulen H-J, Meinel T, Pichlmeier U, Schumacher W, Tonn $\mathrm{J}-\mathrm{C}$, et al. Extent of resection and survival in glioblastoma multiforme:
Together with wide-field imaging techniques such as MRI and low-power surgical microscopy, we have provided a perspective that the use of intraoperative high-resolution microscopy within the surgical armamentarium should yield significant improvements in glioma patient outcomes.

\section{DATA AVAILABILITY}

No datasets were generated or analyzed for this study.

\section{AUTHOR CONTRIBUTIONS}

All authors listed have made a substantial, direct and intellectual contribution to the work, and approved it for publication.

\section{FUNDING}

We acknowledge funding support from the $\mathrm{NIH}$, including grants from the NIDCR (R01 DE023497), the NCI (R01 CA175391), and the NINDS (R01 NS082745). identification of and adjustment for bias. Neurosurgery. (2008) 62:564-76; discussion-76. doi: 10.1227/01.neu.0000317304.31579.17

12. DAmico RS, Englander ZK, Canoll P, Bruce JN. Extent of resection in glioma-a review of the cutting edge. World Neurosurg. (2017) 103:53849. doi: 10.1016/j.wneu.2017.04.041

13. Hervey-Jumper SL, Berger MS. Maximizing safe resection of low- and high-grade glioma. J Neurooncol. (2016) 130:26982. doi: 10.1007/s11060-016-2110-4

14. Sanai N, Berger MS. Operative techniques for gliomas and the value of extent of resection. Neurother J Am Soc Exp NeuroTher. (2009) 6:47886. doi: 10.1016/j.nurt.2009.04.005

15. Brown PD, Maurer MJ, Rummans TA, Pollock BE, Ballman KV, Sloan JA, et al. A prospective study of quality of life in adults with newly diagnosed high-grade gliomas: the impact of the extent of resection on quality of life and survival. Neurosurgery. (2005) 57:495-504- discussion 495-504. doi: 10.1227/01.NEU.0000170562.25335.C7

16. Chaichana KL, Halthore AN, Parker SL, Olivi A, Weingart JD, Brem H, et al. Factors involved in maintaining prolonged functional independence following supratentorial glioblastoma resection. J Neurosurg. (2011) 114:60412. doi: 10.3171/2010.4.JNS091340

17. Chaichana KL, Kosztowski T, Niranjan A, Olivi A, Weingart JD, Laterra J, et al. Prognostic significance of contrast-enhancing anaplastic astrocytomas in adults. J Neurosurg. (2010) 113:286-92. doi: 10.3171/2010.2.JNS091010

18. Stark AM, Nabavi A, Mehdorn HM, Blömer U. Glioblastoma multiformereport of 267 cases treated at a single institution. Surg Neurol. (2005) 63:162-9discussion 9. doi: 10.1016/j.surneu.2004.01.028

19. Ushio Y, Kochi M, Hamada J-i, Kai Y, Nakamura H. Effect of surgical removal on survival and quality of life in patients with supratentorial glioblastoma. Neurol Med Chir. (2005) 45:454-60- discussion 60-1. doi: 10.2176/nmc.45.454

20. Patel T, Bander ED, Venn RA, Powell T, Cederquist GY-M, Schaefer PM, et al. The role of extent of resection in IDH1 wild-type or mutant low-grade gliomas. Neurosurgery. (2018) 82:808-14. doi: 10.1093/neuros/ nyx 265

21. Wijnenga MMJ, French PJ, Dubbink HJ, Dinjens WNM, Atmodimedjo PN, Kros JM, et al. The impact of surgery in molecularly defined low-grade glioma: an integrated clinical, radiological, and molecular analysis. Neuro-Oncology. (2018) 20:103-12. doi: 10.1093/neuonc/nox176

22. Valdes PA, Leblond F, Kim A, Harris BT, Wilson BC, Fan XY, et al. Quantitative fluorescence in intracranial tumor: implications for ALAinduced PpIX as an intraoperative biomarker. J Neurosurg. (2011) 115:117. doi: 10.3171/2011.2.JNS101451 
23. Stummer W, Tonn JC, Goetz C, Ullrich W, Stepp H, Bink A, et al. 5Aminolevulinic acid-derived tumor fluorescence: the diagnostic accuracy of visible fluorescence qualities as corroborated by spectrometry and histology and postoperative imaging. Neurosurgery. (2014) 74:310-9; discussion 920. doi: 10.1227/NEU.0000000000000267

24. Stummer W, Novotny A, Stepp H, Goetz C, Bise K, Reulen HJ. Fluorescenceguided resection of glioblastoma multiforme by using 5 -aminolevulinic acid-induced porphyrins: a prospective study in 52 consecutive patients. J Neurosurg. (2000) 93:1003-13. doi: 10.3171/jns.2000.93. 6.1003

25. Panciani PP, Fontanella M, Schatlo B, Garbossa D, Agnoletti A, Ducati A, et al. Fluorescence and image guided resection in high grade glioma. Clin Neurol Neurosurg. (2012) 114:37-41. doi: 10.1016/j.clineuro.2011.09.001

26. Yamada S, Muragaki Y, Maruyama T, Komori T, Okada Y. Role of neurochemical navigation with 5 -aminolevulinic acid during intraoperative MRI-guided resection of intracranial malignant gliomas. Clin Neurol Neurosurg. (2015) 130:134-9. doi: 10.1016/j.clineuro.2015.01.005

27. Roberts DW, Valdes PA, Harris BT, Fontaine KM, Hartov A, Fan $\mathrm{X}$, et al. Coregistered fluorescence-enhanced tumor resection of malignant glioma: relationships between delta-aminolevulinic acidinduced protoporphyrin IX fluorescence, magnetic resonance imaging enhancement, and neuropathological parameters. J Neurosurg. (2011) 114:595-603. doi: 10.3171/2010.2.JNS091322

28. Diez Valle R, Tejada Solis S, Idoate Gastearena MA, Garcia de Eulate R, Dominguez Echavarri P, Aristu Mendiroz J. Surgery guided by 5aminolevulinic fluorescence in glioblastoma: volumetric analysis of extent of resection in single-center experience. J Neurooncol. (2011) 102:10513. doi: 10.1007/s11060-010-0296-4

29. Hefti M, von Campe G, Moschopulos M, Siegner A, Looser H, Landolt H. 5-aminolevulinic acid induced protoporphyrin IX fluorescence in high-grade glioma surgery: a one-year experience at a single institutuion. Swiss Med Wkly. (2008) 138:180-5.

30. Acerbi F, Broggi M, Eoli M, Anghileri E, Cuppini L, Pollo B, et al. Fluoresceinguided surgery for grade IV gliomas with a dedicated filter on the surgical microscope: preliminary results in 12 cases. Acta Neurochir. (2013) 155:127786. doi: 10.1007/s00701-013-1734-9

31. Tsugu A, Ishizaka H, Mizokami Y, Osada T, Baba T, Yoshiyama M, et al. Impact of the combination of 5-aminolevulinic acid-induced fluorescence with intraoperative magnetic resonance imaging-guided surgery for glioma. World Neurosurg. (2011) 76:120-7. doi: 10.1016/j.wneu.2011.02.005

32. Hadjipanayis CG, Widhalm G, Stummer W. What is the surgical benefit of utilizing 5-aminolevulinic acid for fluorescenceguided surgery of malignant gliomas? Neurosurgery. (2015) 77:663-73. doi: 10.1227/NEU.0000000000000929

33. Rapp M, Kamp M, Steiger HJ, Sabel M. Endoscopic-assisted visualization of 5-aminolevulinic acid-induced fluorescence in malignant glioma surgery: a technical note. World Neurosurg. (2014) 82:E277-E9. doi: 10.1016/j.wneu.2013.07.002

34. Belloch JP, Rovira V, Llacer JL, Riesgo PA, Cremades A. Fluorescence-guided surgery in high grade gliomas using an exoscope system. Acta Neurochir. (2014) 156:653-60. doi: 10.1007/s00701-013-1976-6

35. Liao H, Noguchi M, Maruyama T, Muragaki Y, Kobayashi E, Iseki $\mathrm{H}$, et al. An integrated diagnosis and therapeutic system using intraoperative 5-aminolevulinic-acid-induced fluorescence guided robotic laser ablation for precision neurosurgery. Med Image Anal. (2012) 16:75466. doi: 10.1016/j.media.2010.11.004

36. Nabavi A, Thurm H, Zountsas B, Pietsch T, Lanfermann H, Pichlmeier $\mathrm{U}$, et al. Five-aminolevulinic acid for fluorescence-guided resection of recurrent malignant gliomas: a phase ii study. Neurosurgery. (2009) 65:1070-6; discussion 6-7. doi: 10.1227/01.NEU.0000360128.03597.C7

37. Stummer W, Pichlmeier U, Meinel T, Wiestler OD, Zanella F, Reulen $\mathrm{H}-\mathrm{J}$, et al. Fluorescence-guided surgery with 5-aminolevulinic acid for resection of malignant glioma: a randomised controlled multicentre phase III trial. Lancet Oncol. (2006) 7:392-401. doi: 10.1016/S1470-2045(06) 70665-9

38. Tonn J-C, Stummer W. Fluorescence-guided resection of malignant gliomas using 5-aminolevulinic acid: practical use, risks, and pitfalls. Clin Neurosurg. (2008) 55:20-6.
39. Duffner F, Ritz R, Freudenstein D, Weller M, Dietz K, Wessels J. Specific intensity imaging for glioblastoma and neural cell cultures with 5aminolevulinic acid-derived protoporphyrin IX. J Neurooncol. (2005) 71:10711. doi: $10.1007 / \mathrm{s} 11060-004-9603-2$

40. Gibbs SL, Chen B, O'Hara JA, Hoopes PJ, Hasan T, Pogue BW. Protoporphyrin IX level correlates with number of mitochondria, but increase in production correlates with tumor cell size. Photochem Photobiol. (2006) 82:133441. doi: 10.1562/2006-03-11-RA-843

41. Olivo M, Wilson BC. Mapping ALA-induced PPIX fluorescence in normal brain and brain tumour using confocal fluorescence microscopy. Int J Oncol. (2004) 25:37-45. doi: 10.3892/ijo.25.1.37

42. Stummer W, Stocker S, Novotny A, Heimann A, Sauer O, Kempski O, et al. In vitro and in vivo porphyrin accumulation by C6 glioma cells after exposure to 5-aminolevulinic acid. J Photochem Photobiol B Biol. (1998) 45:160-9. doi: 10.1016/S1011-1344(98)00176-6

43. Stepp H, Stummer W. 5-ALA in the management of malignant glioma. Lasers Surg Med. (2018) 50:399-419. doi: 10.1002/lsm.22933

44. Aminolevulinic acid hydrochloride, known as ALA $\mathrm{HCl}$ (Gleolan, NX Development Corp.) as an optical imaging agent indicated in patients with gliomas (2017).

45. Lau D, Hervey-Jumper SL, Chang S, Molinaro AM, McDermott MW, Phillips $\mathrm{JJ}$, et al. A prospective Phase II clinical trial of 5 -aminolevulinic acid to assess the correlation of intraoperative fluorescence intensity and degree of histologic cellularity during resection of high-grade gliomas. J Neurosurg. (2016) 124:1300-9. doi: 10.3171/2015.5.JNS1577

46. Valdes PA, Leblond F, Jacobs VL, Wilson BC, Paulsen KD, Roberts DW. Quantitative, spectrally-resolved intraoperative fluorescence imaging. Sci Rep. (2012) 2:798. doi: 10.1038/srep00798

47. Wei L, Roberts D, Sanai N, Liu JTC. Visualization technologies for 5-ALA-based fluorescence-guided surgeries. J Neuro-Oncol. (2019) 2019:9. doi: 10.1007/s11060-018-03077-9

48. Haj-Hosseini N, Richter J, Andersson-Engels S, Wardell K. Optical touch pointer for fluorescence guided glioblastoma resection using 5-aminolevulinic acid. Lasers Surg Med. (2010) 42:9-14. doi: 10.1002/1sm.20868

49. Kim A, Khurana M, Moriyama Y, Wilson BC. Quantification of in vivo fluorescence decoupled from the effects of tissue optical properties using fiber-optic spectroscopy measurements. J Biomed Optics. (2010) 15:6. doi: $10.1117 / 1.3523616$

50. Ishihara R, Katayama Y, Watanabe T, Yoshino A, Fukushima T, Sakatani K. Quantitative spectroscopic analysis of 5-aminolevulinic acid-induced protoporphyrin IX fluorescence intensity in diffusely infiltrating astrocytomas. Neurol Med Chir. (2007) 47:53-7; discussion 7. doi: $10.2176 /$ nmc. 47.53

51. Utsuki S, Oka H, Sato S, Suzuki S, Shimizu S, Tanaka S, et al. Possibility of using laser spectroscopy for the intraoperative detection of nonfluorescing brain tumors and the boundaries of brain tumor infiltrates - Technical note. $J$ Neurosurg. (2006) 104:618-20. doi: 10.3171/jns.2006.104.4.618

52. Valdes PA, Kim A, Brantsch M, Niu C, Moses ZB, Tosteson TD, et al. deltaaminolevulinic acid-induced protoporphyrin IX concentration correlates with histopathologic markers of malignancy in human gliomas: the need for quantitative fluorescence-guided resection to identify regions of increasing malignancy. Neuro Oncol. (2011) 13:846-56. doi: 10.1093/neuonc/nor086

53. Belykh E, Miller EJ, Hu D, Martirosyan NL, Woolf EC, Scheck $\mathrm{AC}$, et al. Scanning fiber endoscope improves detection of 5aminolevulinic acid-induced protoporphyrin IX fluorescence at the boundary of infiltrative glioma. World Neurosurg. (2018) 113:e51-e69. doi: 10.1016/j.wneu.2018.01.151

54. Valdes PA, Jacobs V, Harris BT, Wilson BC, Leblond F, Paulsen KD, et al. Quantitative fluorescence using 5-aminolevulinic acid-induced protoporphyrin IX biomarker as a surgical adjunct in low-grade glioma surgery. J Neurosurg. (2015) 123:771-80. doi: 10.3171/2014.12. JNS14391

55. Sanai N, Snyder LA, Honea NJ, Coons SW, Eschbacher JM, Smith KA, et al. Intraoperative confocal microscopy in the visualization of 5-aminolevulinic acid fluorescence in low-grade gliomas. J Neurosurg. (2011) 115:7408. doi: 10.3171/2011.6.JNS11252

56. Wei L, Chen Y, Yin C, Borwege S, Sanai N, Liu JTC. Opticalsectioning microscopy of protoporphyrin IX fluorescence in human gliomas: 
standardization and quantitative comparison with histology. J Biomed Opt. (2017) 22:46005. doi: 10.1117/1.JBO.22.4.046005

57. Wei L, Yin C, Fujita Y, Sanai N, Liu JTC. Handheld line-scanned dual-axis confocal microscope with pistoned MEMS actuation for flat-field fluorescence imaging. Opt Lett. (2019) 44:671-4. doi: 10.1364/OL.44.000671

58. Conchello JA, Lichtman JW. Optical sectioning microscopy. Nat Methods. (2005) 2:920-31. doi: 10.1038/nmeth815

59. Helmchen F, Denk W. Deep tissue two-photon microscopy. Nat Methods. (2005) 2:932-40. doi: 10.1038/nmeth818

60. Huisken J, Stainier DY. Selective plane illumination microscopy techniques in developmental biology. Development. (2009) 136:1963-75. doi: 10.1242/dev.022426

61. Wei L, Yin C, Liu JTC. Dual-axis confocal microscopy for point-ofcare pathology. IEEE J Select Topics Quantum Electron. (2019) 25:110. doi: 10.1109/JSTQE.2018.2854572

62. Meza D, Wang D, Wang Y, Borwege S, Sanai N, Liu JT. Comparing high-resolution microscopy techniques for potential intraoperative use in guiding low-grade glioma resections. Lasers Surg Med. (2015) 47:28995. doi: 10.1002/lsm.22347

63. Glaser AK, Reder NP, Chen Y, McCarty EF, Yin C, Wei L, et al. Lightsheet microscopy for slide-free non-destructive pathology of large clinical specimens. Nat Biomed Eng. (2017) 1:0084. doi: 10.1038/s41551-017-0084

64. Vercauteren T, Perchant A, Pennec X, Ayache N. Mosaicing of confocal microscopic in vivo soft tissue video sequences. Lect Notes Comput Sc. (2005) 3749:753-60. doi: 10.1007/11566465_93

65. Vercauteren T, Perchant A, Malandain G, Pennec X, Ayache N. Robust mosaicing with correction of motion distortions and tissue deformations for in vivo fibered microscopy. Med Image Anal. (2006) 10:673-92. doi: 10.1016/j.media.2006.06.006

66. Loewke KE, Camarillo DB, Piyawattanametha W, Mandella MJ, Contag CH, Thrun S, et al. In vivo micro-image mosaicing. IEEE T Bio-Med Eng. (2011) 58:159-71. doi: 10.1109/TBME.2010.2085082

67. Kose K, Cordova M, Duffy M, Flores ES, Brooks DH, Rajadhyaksha M. Videomosaicing of reflectance confocal images for examination of extended areas of skin in vivo. Br J Dermatol. (2014) 171:1239-41. doi: 10.1111/bjd.13050

68. Kose K, Gou M, Yelamos O, Cordova M, Rossi AM, Nehal KS, et al. Automated video-mosaicking approach for confocal microscopic imaging in vivo: an approach to address challenges in imaging living tissue and extend field of view. Sci Rep. (2017) 7:10759. doi: 10.1038/s41598-017-11072-9

69. Martirosyan NL, Eschbacher JM, Kalani MYS, Turner JD, Belykh E, Spetzler RF, et al. Prospective evaluation of the utility of intraoperative confocal laser endomicroscopy in patients with brain neoplasms using fluorescein sodium: experience with 74 cases. Neurosurg Focus. (2016) 40:3. doi: 10.3171/2016.1.FOCUS15559

70. Pavlov V, Meyronet D, Meyer-Bisch V, Armoiry X, Pikul B, Dumot $\mathrm{C}$, et al. Intraoperative probe-based confocal laser endomicroscopy in surgery and stereotactic biopsy of low-grade and high-grade gliomas: a feasibility study in humans. Neurosurgery. (2016) 79:604-12. doi: 10.1227/NEU.0000000000001365
71. Belykh E, Cavallo C, Gandhi S, Zhao X, Veljanoski D, Izady Yazdanabadi $M$, et al. Utilization of intraoperative confocal laser endomicroscopy in brain tumor surgery. J Neurosurg Sci. (2018) 2018:8. doi: 10.23736/S0390-5616.18.04553-8

72. Sanai N, Eschbacher J, Hattendorf G, Coons SW, Preul MC, Smith KA, et al. Intraoperative confocal microscopy for brain tumors: a feasibility analysis in humans. Neurosurgery. (2011) 68(2 Suppl Operative):282-90; discussion 90. doi: 10.1227/NEU.0b013e318212464e

73. Eschbacher J, Martirosyan NL, Nakaji P, Sanai N, Preul MC, Smith $\mathrm{KA}$, et al. In vivo intraoperative confocal microscopy for real-time histopathological imaging of brain tumors. J Neurosurg. (2012) 116:85460. doi: 10.3171/2011.12.JNS11696

74. Yano H, Nakayama N, Ohe N, Miwa K, Shinoda J, Iwama T. Pathological analysis of the surgical margins of resected glioblastomas excised using photodynamic visualization with both 5 -aminolevulinic acid and fluorescein sodium. J Neurooncol. (2017) 133:389-97. doi: 10.1007/s11060-0172445-5

75. Yoneda $T$, Nonoguchi N, Ikeda N, Yagi R, Kawabata S, Furuse M, et al. Spectral radiance of protoporphyrin IX fluorescence and its histopathological implications in 5-aminolevulinic acid-guided surgery for glioblastoma. Photomed Laser Surg. (2018) 36:266-72. doi: 10.1089/pho. 2017.4384

76. Konecky SD, Owen CM, Rice T, Valdes PA, Kolste K, Wilson BC, et al. Spatial frequency domain tomography of protoporphyrin IX fluorescence in preclinical glioma models. J Biomed Opt. (2012) 17:056008. doi: 10.1117/1.JBO.17.5.056008

77. Roberts DW, Olson JD, Evans LT, Kolste KK, Kanick SC, Fan X, et al. Red-light excitation of protoporphyrin IX fluorescence for subsurface tumor detection. J Neurosurg. (2018) 128:1690-7. doi: 10.3171/2017.1.JNS162061

78. Kolste KK, Kanick SC, Valdes PA, Jermyn M, Wilson BC, Roberts DW, et al. Macroscopic optical imaging technique for wide-field estimation of fluorescence depth in optically turbid media for application in brain tumor surgical guidance. J Biomed Opt. (2015) 20:26002. doi: 10.1117/1.JBO.20.2.026002

Conflict of Interest Statement: The authors declare that the research was conducted in the absence of any commercial or financial relationships that could be construed as a potential conflict of interest.

The handling editor declared a shared institutional affiliation, though no other collaboration, with several of the authors (YF, NS).

Copyright (c) 2019 Wei, Fujita, Sanai and Liu. This is an open-access article distributed under the terms of the Creative Commons Attribution License (CC BY). The use, distribution or reproduction in other forums is permitted, provided the original author(s) and the copyright owner(s) are credited and that the original publication in this journal is cited, in accordance with accepted academic practice. No use, distribution or reproduction is permitted which does not comply with these terms. 